\title{
FAKTOR-FAKTOR YANG MEMPENGARUHI ANGKA KEMATIAN BALITA DI PROVINSI PAPUA
}

Analisis Survei Penduduk Antar Sensus tahun 2015

\author{
(Factors That Influence Under-Five Child Mortality in Papua, \\ Analysis of Intercensal Population Survey 2015)
}

\author{
Mieke Nurmalasari ${ }^{1}$, Linta Ifada ${ }^{2}$, Setia Pramana ${ }^{3}$ \\ ${ }^{1}$ Universitas Esa Unggul \\ 2 Badan Pusat Statistik \\ ${ }^{3}$ Politeknik Statistika STIS \\ Jl. Arjuna Utara no 9, Duri Kepa, Kebon Jeruk, Jakarta Barat, 11510, Indonesia \\ E-mail: mieke@esaungqul.ac.id
}

\begin{abstract}
ABSTRAK
Usaha untuk menurunkan Angka Kematian Bayi (AKB) dan Angka Kematian Anak Bawah Lima Tahun (AKABA) masih terus dilakukan meskipun secara global sudah mengalami penurunan. Kematian bayi dan balita merupakan masalah kesehatan yang penting di Indonesia terutama bagi wilayah Indonesia di bagian timur karena angka kematian keduanya masih tinggi. Salah satu agenda dari Sustainable Development Goals (SGDs) adalah menurunkan angka kematian bayi menjadi paling tidak 12/1000 kelahiran pada tahun 2030. Penelitian ini bertujuan untuk mengidentifikasikan faktor-faktor yang mempengaruhi angka kematian balita di Propinsi Papua dilihat dari karakteristik individu ibu, anak yang dilahirkan dan lingkungannya berdasarkan data SUPAS 2015. Metode yang digunakan adalah analisis regresi logistik. Hasil penelitian ini menunjukkan bahwa faktor pendidikan ibu, interval melahirkan sebelumnya, jenis atau tipe kelahiran, jenis kelamin, dan sanitasi memberikan pengaruh yang signifikan terhadap kematian balita di Propinsi Papua.
\end{abstract}

Kata kunci: angka kematian balita, regresi logistik, tingkat kematian bayi

\section{ABSTRACT}

The effort to reduce the Infant Mortality Rate (IMR) and Under-Five Child Mortality Rate continue to be carried out even though globally it has decreased. Infant and Child under-five child mortality is an important health problem in Indonesia, especially for eastern area of Indonesia, because both mortality rate still high. One of the agendas of the Sustainable Development Goals (SGDs) is to reduce the infant mortality rate to at least 12/1000 births in 2030. This study aims to identify factors that influence under-five child mortality in Papua Province in terms of the characteristics of individual mothers, children born and its environment based on 2015 SUPAS data. Logistic regression analysis methods were used to identify the factors. The result indicates that maternal education factors, previous childbirth intervals, type of birth, gender and sanitation have a significant effect on under-five children mortality in Papua Province.

Keywords: under-five child mortality, logistic regression, infant mortality rate

\section{PENDAHULUAN}

Suatu negara dapat dilihat tingkat kesejahteraan dan kesehatannya dari tiga indikator berikut: (1) Angka kematian neonatal (AKN), (2) angka kematian bayi (AKB), dan (3) angka kematian balita (AKABA). Ketiga indikator ini menggambarkan secara umum kualitas hidup dan pelayanan kesehatan di suatu wilayah. Indikator kematian anak yang memegang peranan penting salah satunya adalah Angka Kematian Balita (AKABA), menurut definisi AKABA adalah banyaknya kematian bayi berusia di bawah lima tahun, per 1000 kelahiran hidup pada satu tahun tertentu. AKABA di Indonesia masih tertinggi di antara negara ASEAN. Berdasarkan SUPAS atau Survei Penduduk Antar Sensus tahun 2015, nilai AKABA sebesar 26,29 per 1000 kelahiran hidup. Angka ini telah lebih kecil dari batas 
minimum target Millennium Development Goals (MGDs) Tahun 2015 sebesar 32 per 1000 kelahiran hidup (Indonesian Ministry of Health, 2018). Survei Demografi dan Kesehatan Indonesia (SDKI) tahun 2017 juga menunjukkan bahwa AKB di Indonesia mengalami penurunan meskipun masih tergolong tinggi dari negara-negara lain di ASEAN. Penurunan tersebut yaitu 32/1000 kelahiran pada tahun 2017, turun dari sebelumnya yaitu 40/1000 pada tahun 2014. Meskipun ada tren penurunan dari tahun ke tahun, tetapi usaha untuk menurunkan AKB dan AKABA terus diupayakan agar semakin kecil (BKKBN, 2017). AKB dan AKABA menjadi salah satu indikator dalam Rencana Pembangunan Jangka Menengah Nasional (RPJMN) 2015-2018 dengan target 24 per 1.000 kelahiran hidup dan sekarang menurut RPJMN 2020-2024 targetnya adalah 16 per 1.000 kelahiran hidup (Republik Indonesia, 2015). Salah satu agenda dari Sustainable Development Goals (SGDs) adalah menurunkan Angka kematian bayi menjadi sekurang-kurangnya 12/1000 kelahiran pada tahun 2030.

Angka kematian balita secara keseluruhan belum merata, masih ada yang naik atau turun di seluruh propinsi di Indonesia. AKABA yang tinggi masih didominasi oleh Propinsi di wilayah Indonesia Timur, salah satunya adalah Propinsi Papua. Angka kematian balita di Propinsi Papua termasuk tinggi pertama di wilayah Indonesia Timur. Menurut data dari SDKI 2002, AKB per 1000 kelahiran hidup di Propinsi Papua adalah 56, kemudian turun menjadi 41 di tahun 2007 dan naik lagi menjadi 54 di tahun 2012 (Kesehatan \& Papua, 2017). Terdapat banyak faktor yang mempengaruhi AKABA antara lain faktor ibu, faktor bayi, ketersediaan pelayanan kesehatan dan kondisi sosial ekonomi. Studi ini bertujuan untuk mengetahui faktor apa saja yang mempengaruhi angka kematian balita di Propinsi Papua dilihat dari karakteristik individu ibu, anak yang dilahirkan dan lingkungannya.

\section{METODE}

\section{Data dan Variabel}

Data yang digunakan dalam penelitian ini adalah data sekunder yang berasal dari Survei Penduduk Antar Sensus (SUPAS) tahun 2015. Pengumpulan data SUPAS dilakukan oleh Badan Pusat Statistik (BPS) dengan unit sampelnya adalah rumah tangga. Wilayah yang menjadi perhatian peneliti adalah Provinsi Papua. Pengumpulan data SUPAS diperoleh dari rumah tangga terpilih melalui proses wawancara. Cakupan dalam penelitian ini adalah seluruh rumah tangga di Papua yang mempunyai anak di bawah umur lima tahun yang lahir dari tahun 2010 sampai dengan 2015.

Penyebab kematian balita di Papua ingin dilihat dari beberapa faktor yang diduga memiliki keterkaitan dengan variabel responnya diantaranya faktor demografi ibu, sosial ekonomi dan kesehatan lingkungan. Variabel dependen atau respon dalam penelitian ini adalah status hidup balita ( $1=$ meninggal dan $0=$ masih hidup). Variabel independen adalah: 1 . Tingkat Pendidikan Ibu dikategorikan dalam 3 tingkatan yaitu rendah (tidak punya ijazah SD/MI atau sederajat), menengah (SMP/MTS atau SMA/MA atau sederajat) dan tinggi (Lulusan Diploma, S1/S2/S3), 2. Status Bekerja Ibu (Bekerja dan tidak bekerja), 3. Usia Persalinan Pertama ( $<20$ tahun, $20-35$ tahun dan $>35$ tahun), usia persalinan 20-35 tahun adalah usia persalinan yang ideal, 4. Interval Melahirkan Sebelumnya ( $<24$ bulan dan $\geq 24$ bulan), 5. Tipe Kelahiran (Tunggal dan Kembar), Jenis Kelamin Anak yang dilahirkan ( Laki-laki dan Perempuan), 7. Klasifikasi tempat tinggal (pedesaan dan perkotaan), 8. Sumber air minum (kurang layak dan layak), 9. Sanitasi (jamban sendiri, jamban bersama, jamban umum dan tidak ada jamban).

\section{Metode Statistika}

Analisis deskriptif dan inferensia digunakan dalam penelitian ini. Analisa deskriptif dilakukan untuk mengetahui gambaran umum tentang data yang akan diteliti, eksplorasi awal penting dilakukan untuk melihat pola dan sebaran data. Analisa Inferensia dilakukan dengan menggunakan metode Regresi Logistik karena variabel respon (outcome variable) dalam penelitian merupakan status hidup bayi yang merupakan variabel dikotomi $(0=$ masih hidup dan $1=$ meninggal $)$, sehingga metode regresi logistik dapat digunakan untuk mengetahui ada tidaknya pengaruh dari faktor demografi ibu terhadap status hidup balita meninggal atau hidup. 
Secara umum model regresi logistik pada studi ini merupakan probabilitas bersyarat kejadian kematian balita dengan syarat variabel bebasnya dinotasikan dengan $P\left(Y_{i}=1 / x_{i}\right)=\pi_{i}$. Ekspresi $\pi_{i}$ dalam model regresi logistic dapat dituliskan sebagai berikut (Agresti, 2002) dan (Pramana Setia, Yuniarto Budi, Mariyah Siti, Santoso Ibnu, 2018):

$$
\pi_{i}=\frac{\exp \left(\beta_{0}+\beta_{1} x_{i 1}+\cdots+\beta_{p} x_{i p}\right)}{1+\exp \left(\beta_{0}+\beta_{1} x_{i 1}+\cdots+\beta_{p} x_{i p}\right)}
$$

dimana:

$\pi_{i}=$ peluang jika balita ke-i akan meninggal dengan syarat himpunan variabel bebas $X_{\mathrm{i}}$

$Y_{i}=$ variabel respon yaitu status hidup balita ke-i (hidup atau meninggal), $i=1, \ldots, n$

$x_{i}=$ variabel bebas atau variabel prediktor

$\beta_{j}=$ koefisien regresi logistik termasuk juga nilai konstanta, $j=0, \ldots, p$.

Persamaan regresi logistik dalam Persamaan 1 dapat ditulis dalam bentuk lain yaitu dalam bentuk transformasi logit, karena dalam regresi logistik hubungan antara variabel independen dengan variabel dependen tidak linier sehingga perlu ditransformasi logit menjadi Persamaan 2 di bawah ini:

$$
\operatorname{logit}\left(\pi_{i}\right)=\log \left(\frac{\pi_{i}}{1-\pi_{i}}\right)=\beta_{0}+\beta_{1} x_{i 1}+\cdots+\beta_{p} x_{i p}
$$

dimana

$\pi_{i}=$ peluang jika balita ke-i akan meninggal,

1- $\pi_{i}=$ peluang balita ke $\mathrm{i}$ tetap hidup,

$\beta_{j}=$ koefisien regresi logistik termasuk juga nilai konstanta, $j=0, \ldots, p$,

$x_{i}=$ variabel bebas atau variabel prediktor.

Tahap awal analisis regresi logistik, semua variabel yang menjadi perhatian peneliti dimasukkan ke dalam model regresi logistik, kemudian variabel yang tidak signifikan pengaruhnya di tahap pertama dikeluarkan dari model. Untuk uji kebaikan model menggunakan uji hosmer-lemeshow dan untuk uji kebermaknaan predictor menggunakan uji Wald. Proses selanjutnya adalah seleksi variabel untuk mendapatkan model terbaik dengan menggunakan metode forward selection. Analisa dilakukan menggunakan software R (R Core Team, 2018) dan (Pramana Setia, Yordani Ricky, Kurniawan Robert, 2017).

\section{HASIL DAN PEMBAHASAN}

Hasil analisa deskriptif menunjukkan bahwa jumlah balita yang ada di dalam sampel SUPAS 2015 di Propinsi Papua sebanyak 6,008 balita dengan status balita yang masih hidup dan telah meninggal masing-masing sebesar 5,399 (89,9\%) dan 609 (10,1\%). Angka prevalensi kematian balita di Papua ini masih tergolong tinggi, oleh karena itu eksplorasi data berikutnya adalah melihat gambaran distribusi kematian balita di Propinsi Papua dilihat dari faktor-faktor terkait yang ditampilkan dalam Tabel 1. Dilihat dari faktor pendidikan ibu, persentase kematian balita terbesar ada pada ibu dengan pendidikan rendah yaitu sebesar 12,6 . Selain itu, kematian balita banyak terjadi pada usia persalinan pertama yang beresiko atau rawan yaitu di usia di bawah 20 tahun $(11,2 \%)$ dan usia diatas 35 tahun (13,7\%). Kemudian berdasarkan faktor interval kelahiran sebelumnya, persentase kematian balita lebih banyak terjadi pada ibu yang mempunyai interval melahirkan yang pendek.

Persentase kematian balita kembar lebih tinggi dibandingkan dengan balita kelahiran tunggal. Persentase kematian balita perempuan lebih rendah dibandingkan balita laki-laki. Sedangkan untuk lokasi tempat tinggal, persentase balita yang meninggal di pedesaan lebih tinggi hampir 2 kali lipat dibandingkan di perkotaan. Selanjutnya persentase kematian balita yang berasal dari keluarga atau rumah tangga yang tidak memiliki jamban dan menggunakan jamban bersama lebih tinggi dari pada 
yang memiliki jamban sendiri dan umum. Sedangkan untuk sumber air minum terlihat tidak ada perbedaan persentase kematian balita.

Prevalensi kematian balita dilihat dari status bekerja ibu terlihat hampir sama, sehingga diduga faktor ini tidak terlalu berpengaruh, tapi harus dibuktikan pada analisis selanjutnya yaitu analisis inferensia. Hal serupa terjadi pada faktor sumber air minum, terlihat persentasi tidak jauh berbeda.

Tabel 1. Distribusi Kematian Balita Berdasarkan Variabel yang Diamati.

\begin{tabular}{|c|c|c|c|}
\hline \multirow[b]{2}{*}{ Variabel } & \multicolumn{3}{|c|}{ Status Hidup Balita } \\
\hline & $\begin{array}{l}\text { Hidup } \\
\mathrm{N}(\%)\end{array}$ & $\begin{array}{c}\text { Meninggal } \\
\mathrm{N}(\%)\end{array}$ & $\begin{array}{c}\text { Total } \\
\text { N (\%) }\end{array}$ \\
\hline \multicolumn{4}{|l|}{ Pendidikan Ibu: } \\
\hline Rendah $(\leq \mathrm{SD})$ & $2584(87,4 \%)$ & $374(12,6 \%)$ & $2958(100 \%)$ \\
\hline Menengah (SMP-SMA) & $2365(92,1 \%)$ & $203(7,9 \%)$ & $2568(100 \%)$ \\
\hline Tinggi (Diploma atau PT) & $450(93,4 \%)$ & $32(6,6 \%)$ & $482(100 \%)$ \\
\hline \multicolumn{4}{|l|}{ Status Bekerja Ibu: } \\
\hline Tidak Bekerja & $2436(90,2 \%)$ & $264(9,8 \%)$ & $2700(100 \%)$ \\
\hline Bekerja & $2963(89,6 \%)$ & $345(10,4 \%)$ & $3308(100 \%)$ \\
\hline \multicolumn{4}{|l|}{ Usia Persalinan Pertama: } \\
\hline$<20$ Tahun & $1789(88,8 \%)$ & $225(11,2 \%)$ & $2014(100 \%)$ \\
\hline 20 - 35 Tahun & $3565(90,4 \%)$ & $377(9,6 \%)$ & $3942(100 \%)$ \\
\hline$>35$ Tahun & $44(86,3 \%)$ & $7(13,7 \%)$ & $51(100 \%)$ \\
\hline \multicolumn{4}{|l|}{ Interval Melahirkan Sebelumnya } \\
\hline$<24$ Bulan & $1907(88,4 \%)$ & $251(11,6 \%)$ & $2158(100 \%)$ \\
\hline$\geq 24$ Bulan & $3492(90,7 \%)$ & $358(9,3 \%)$ & $3850(100 \%)$ \\
\hline \multicolumn{4}{|l|}{ Jenis Kelahiran } \\
\hline Tunggal & $5325(90,3 \%)$ & $574(9,7 \%)$ & $5899(100 \%)$ \\
\hline Kembar & $74(67,9 \%)$ & $35(32,1 \%)$ & $109(100 \%)$ \\
\hline \multicolumn{4}{|l|}{ Jenis Kelamin Anak } \\
\hline Laki-Laki & $2762(89 \%)$ & $342(11 \%)$ & $3104(100 \%)$ \\
\hline Perempuan & $2637(90,8 \%)$ & $267(9,2 \%)$ & $2904(100 \%)$ \\
\hline \multicolumn{4}{|l|}{ Tempat Tinggal } \\
\hline Pedesaan & $3897(88,9 \%)$ & $485(11,1 \%)$ & $4382(100 \%)$ \\
\hline Perkotaan & $1502(92,4 \%)$ & $124(7,6 \%)$ & $1626(100 \%)$ \\
\hline \multicolumn{4}{|l|}{ Sumber Air Minum } \\
\hline Kurang Layak & $3239(90,2 \%)$ & $352(9,8 \%)$ & $3591(100 \%)$ \\
\hline Layak & $2160(89,4 \%)$ & $257(10,6 \%)$ & $2417(100 \%)$ \\
\hline \multicolumn{4}{|l|}{ Sanitasi } \\
\hline Jamban Sendiri & $3394(91,4 \%)$ & $320(8,6 \%)$ & $3714(100 \%)$ \\
\hline Jamban Bersama & $465(87,1 \%)$ & $69(12,9 \%)$ & $534(100 \%)$ \\
\hline Jamban Umum & $213(91,8 \%)$ & $19(8,2 \%)$ & $232(100 \%)$ \\
\hline Tidak Ada & $1327(86,8 \%)$ & $201(13,2 \%)$ & $1528(100 \%)$ \\
\hline
\end{tabular}

Sumber: Data SUPAS 2015.

Seleksi variabel untuk mendapatkan model terbaik dilakukan dengan menggunakan forward selection (dengan Wald test) dan diperoleh model akhir analisis regresi logistik pada Tabel 2. Pada tingkat signifikansi $\alpha=5 \%$ diperoleh faktor yang signifikan pengaruhnya terhadap Angka kematian Balita (AKABA) di Propinsi Papua adalah pendidikan ibu, interval melahirkan sebelumnya, jenis kelahiran, jenis kelamin, dan sanitasi.

Pendidikan ibu memberikan kontribusi atau pengaruh yang signifikan terhadap kematian balita. Hal ini selaras dengan tahap eksplorasi data di Tabel 1, yang menunjukkan bahwa persentase kematian balita lebih besar pada Ibu yang berpendidikan rendah. Terlihat pada Tabel 2, balita dengan Ibu yang tingkat pendidikan lebih tinggi, memiliki kecenderungan lebih kecil untuk meninggal dibandingkan dengan balita dengan ibu yang jenjang pendidikannya rendah. Balita dengan Ibu yang tingkat pendidikan menengah mempunyai kecenderungan untuk meninggal lebih kecil sebesar 0.616 kali dibandingkan dengan balita dengan balita dengan ibu berpendidikan rendah. Dengan kata lain balita dengan ibu dengan pendidikan menengah mempunyai kecenderungan balitanya tetap hidup 1,623 kali lebih besar dibandingkan dengan dengan ibu yang pendidikannya 
rendah, demikian juga untuk ibu yang pendidikan tinggi (ijazah terakhirnya adalah diploma atau S1/S2/S3) mempunyai kecenderungan lebih tinggi 1,13 kali balita tetap hidup dibandingkan dengan ibu berpendidikan rendah. Ibu yang berpendidikan menengah maupun tinggi mempunyai keingin tahuan lebih untuk mencari informasi atau pengetahuan tentang pemeliharaan kesehatan. Hasil yang sama tentang tingkat pendidikan ibu sangat berpengaruh pada kematian balita adalah penelitian dari (Aheto, 2019).

Tabel 2. Hasil Analisis Regresi Logistik Berganda

\begin{tabular}{|c|c|c|c|}
\hline Variabel & $\beta(\mathrm{Se})$ & Odds Ratio (OR) & p.value \\
\hline Konstanta & $-1,863(0,107)$ & 0,155 & $0,00001^{*}$ \\
\hline \multicolumn{4}{|l|}{ Pendidikan Ibu: } \\
\hline Rendah $(\leq \mathrm{SD})$ & - & - & \\
\hline Menengah (SMP-SMA) & $-0,484(0,099)$ & 0,616 & $0,002 *$ \\
\hline Tinggi (Diploma atau S1/S2/S3) & $-0,606(0,198)$ & 0,545 & 0,538 \\
\hline \multicolumn{4}{|l|}{ Interval Melahirkan Sebelumnya } \\
\hline$<24$ Bulan & - & - & \\
\hline$\geq 24$ Bulan & $-0,246(0,090)$ & 0,782 & $0,006^{*}$ \\
\hline \multicolumn{4}{|l|}{ Jenis Kelahiran } \\
\hline Tunggal & - & - & \\
\hline Kembar & $1,412(0,215)$ & 4,102 & $0,00001 *$ \\
\hline \multicolumn{4}{|l|}{ Jenis Kelamin Anak } \\
\hline Laki-Laki & - & - & \\
\hline Perempuan & $-0,189(0,087)$ & 0,828 & 0,030 \\
\hline \multicolumn{4}{|l|}{ Sanitasi } \\
\hline Jamban Sendiri & - & - & \\
\hline Jamban Bersama & $0,350(0,145)$ & 1,419 & $0,016 *$ \\
\hline Jamban Umum & $-1,52(0,249)$ & 0,859 & 0,541 \\
\hline Tidak Ada & $0,264(0,104)$ & 1,302 & $0,011 *$ \\
\hline
\end{tabular}

Keterangan: - adalah variabel referensi, dan * signifikan pada $\alpha=5 \%$

Anak yang dilahirkan oleh Ibu yang interval melahirkan sebelumnya di atas 24 bulan lebih kecil resikonya untuk meninggal dibandingkan dengan yang interval melahirkan sebelumnya kurang dari 24 bulan $(\mathrm{OR}=0,278)$. Jika seorang ibu memiliki jarak melahirkan minimal 2 tahun atau lebih maka akan ada waktu yang cukup untuk mengembalikan fungsi tubuhnya untuk kehamilan berikutnya, sehingga anak sebelumnya juga mendapatkan asi dan gizi yang cukup dari ibu. (Kayode, Adekanmbi, \& Uthman, 2012) juga mengungkapkan bahwa seorang ibu yang memiliki interval melahirkan dengan kelahiran sebelumnya lebih lama, maka kecenderungan balita untuk meninggal akan berkurang.

Jenis/ tipe kelahiran dengan anak kembar berpeluang lebih besar untuk meninggal 4,102 kali dibandingkan dengan kelahiran tunggal. (Monden \& Smits, 2017) dan (Gebretsadik \& Gabreyohannes, 2016) juga menjelaskan dalam penelitiannya bahwa jenis kelahiran kembar lebih beresiko untuk meninggal dibandingkan kelahiran anak tunggal.

Jika ditinjau dari jenis kelamin, balita perempuan mempunyai peluang hidup lebih besar dengan odds ratio 0,828 dibandingkan dengan balita laki-laki, atau dapat dikatakan bahwa anak laki-laki mempunyai resiko sebesar 1,71 kali lebih tinggi mengalami kematian dibandingkan dengan anak perempuan. Hasil penelitian dari (Ruggieri, Anticoli, D’ambrosio, Giordani, \& Viora, 2016) juga menunjukkan bahwa balita perempuan lebih bisa bertahan hidup dibandingkan balita laki-laki ditinjau dari segi sistem kekebalan tubuh dan faktor genetik. Anak perempuan lebih kebal terhadap penyakit.

Sanitasi atau jenis tempat buang air besar juga memberikan pengaruh yang signifikan terhadap kematian balita, dari Tabel $\mathbf{2}$ menunjukkan hasil bahwa balita yang memiliki akses jamban bersama memiliki resiko mengalami kematian 1,419 kali lebih tinggi dibandingkan dengan balita yang keluarganya mempunyai jamban sendiri. Sama halnya dengan balita yang tidak memiliki akses jamban cenderung mempunyai resiko kematian 1,302 kali lebih besar dibandingkan dengan balita yang mempunyai akses sanitasi jamban sendiri. 


\section{KESIMPULAN}

Berdasarkan hasil uji statistik dari regresi logistik dengan tingkat signifikansi $5 \%$ diperoleh faktor yang signifikan mempengaruhi Angka kematian Balita (AKABA) di Propinsi Papua berdasarkan data SUPAS 2015 adalah pendidikan ibu, interval melahirkan sebelumnya, jenis kelahiran, jenis kelamin, dan sanitasi. Melihat dari faktor-faktor yang signifikan pengaruhnya terhadap AKABA menunjukkan bahwa masih perlu dilakukan peningkatan pengetahuan untuk ibu di wilayah papua agar lebih menjaga jarak atau interval kelahiran dengan sebelumnya. AKABA juga tinggi terjadi pada ibu dengan tingkat pendidikan rendah yaitu ibu-ibu yang tidak sampai selesai sekolah dasar ataupun yang paling tinggi berijazah SD. Penting dilakukan kegiatan penyuluhan atau edukasi mengenai pentingnya menjaga kesehatan untuk ibu dan anak, pemberian ASI ekslusif di usia dua tahun pertama agar anak memiliki sistem kekebalan yang kuat, peningkatan pengetahuan ibu hamil untuk memperoleh pelayanan minimal paling tidak satu kali dalam masa kehamilan. Perbaikan dan pemerataan penyediaan akses sanitasi dan pembuangan air besar perlu ditingkatkan karena prosentase balita di papua yang tidak memiliki jamban sendiri masih tinggi dan masih banyak juga yang menggunakan jamban bersama.

\section{DAFTAR PUSTAKA}

Agresti, A. (2002). Categorical Data Analysis. In Wiley series in probability and statistics. https://doi.org/10.1198/tech.2003.s28

Aheto, J. M. K. (2019). Predictive model and determinants of under-five child mortality: Evidence from the 2014 Ghana demographic and health survey. BMC Public Health, 19(1), 1-10. https://doi.org/10.1186/s12889-019-6390-4

BKKBN. (2017). Sdki 2017. In Survei Demografi dan Kesehatan Indonesia.

Gebretsadik, S., \& Gabreyohannes, E. (2016). Determinants of Under-Five Mortality in High Mortality Regions of Ethiopia: An Analysis of the 2011 Ethiopia Demographic and Health Survey Data. https://doi.org/10.1155/2016/1602761

Indonesian Ministry of Health. (2018). Indonesia Health Profile, 2017. In Ministry of Health Indonesia. Retrieved from website: http://www.kemkes.go.id

Kayode, G. A., Adekanmbi, V. T., \& Uthman, O. A. (2012). Risk factors and a predictive model for under-five mortality in Nigeria: Evidence from Nigeria demographic and health survey. BMC Pregnancy and Childbirth. https://doi.org/10.1186/1471-2393-12-10

Kesehatan, D., \& Papua, P. (2017). PROFIL KESEHATAN PROVINSI PAPUA TAHUN 2016. Retrieved from http://www.depkes.go.id/resources/download/profil/PROFIL_KES_PROVINSI_2016/34_Papua_2016.pdf

Monden, C. W. S., \& Smits, J. (2017). Mortality among twins and singletons in sub-Saharan Africa between 1995 and 2014: a pooled analysis of data from 90 Demographic and Health Surveys in 30 countries. The Lancet Global Health. https://doi.org/10.1016/S2214-109X(17)30197-3

Pramana Setia, Yordani Ricky, Kurniawan Robert, Y. B. (2017). Dasar-dasar Statistika dengan Software $R$ Konsep dan Aplikasi. Bogor: In Media.

Pramana Setia, Yuniarto Budi, Mariyah Siti, Santoso Ibnu, N. R. (2018). Data Mining dengan R (I). Jakarta: In Media.

R Core Team. (2018). R: A Language and Environment for Statistical Computing. R Foundation for Statistical Computing. Retrieved from Vienna website: https://www.r-project.org

Republik Indonesia. (2015). Rencana Pembangunan Jangka Menengah Nasional 2015-2019. Rencana Pembangunan Jangka Menengah Nasional 2015-2019, 313. https://doi.org/10.1017/CBO9781107415324.004

Ruggieri, A., Anticoli, S., D'ambrosio, A., Giordani, L., \& Viora, M. (2016). Monographic section The influence of sex and gender on immunity, infection and vaccination. Ann Ist Super Sanità, 52(2), 198-204. https://doi.org/10.4415/ANN_16_02_11 